\title{
Comparison of the Application of Teaching Methods of Obstetrics and Gynecology Nursing
}

\author{
Xiaona $\operatorname{Jin}^{1, \text { a }}$ \\ ${ }^{1}$ Xi'an International University, Xi'an, Shaanxi, China; Post: 710077 \\ ajinxiaonamv@163.com
}

\begin{abstract}
Keywords: Obstetrics and Gynecology Nursing; LBL Teaching Method; PBL+LBL Dual-track Teaching Method
\end{abstract}

\begin{abstract}
Goal] This paper discusses the use of LBL method, PBL and LBL dual-track teaching method for nursing undergraduate students in the teaching of "Gynecology and Obstetrics Nursing" curriculum, and statistical analysis of the effects of students' acquisition of knowledge and skills. [Method] A systematic sampling method was used to sample 60 students of 2015 nursing students of Xi'an Foreign Affairs Medical College. They were randomly divided into 2 groups of 30 each. They were taught using the LBL teaching method and the PBL+LBL dual-track teaching method. At the end of the course, skills and theoretical assessments will be conducted. [Result] Although there was no significant difference in the scores of the examination and the basic questions between the LBL group and the PBL+LBL group $(\mathrm{P}>0.05)$, the latter was significantly higher than the former in the score of the comprehensive question, and the difference was statistically significant $(\mathrm{P}<0.05)$. [Conclusion] PBL and LBL dual-track teaching method can not only enhance students' mastery of theoretical knowledge, but also enable students to apply the knowledge they have learned to clinical case analysis and practice. The overall quality of students has been improved.
\end{abstract}

\section{Introduction}

Obstetrics and Gynecology Nursing is the main subject of clinical nursing teaching in medical colleges and universities. It is an independent discipline covering a wide range of clinical nursing medicine. It is a compulsory course for nursing students that is in line with nursing science, surgery and pediatrics ${ }^{[1]}$. For a long time, during the theoretical teaching, the nursing medical education has always used the teacher-based monologue method, implemented the "fed duck" method and completed the teaching with the teaching mode taught according to the teaching sequence. Students are busy with theoretical indoctrination and reciting for exams after class, they have no pre-class preparations, think and participate in class hours, classroom atmosphere is not active, students are prone to boredom and numbness, and theory and practice are separated ${ }^{[2]}$. At present, many medical colleges still use lecture-based learning (LBL).

With the development of modern medicine, training an outstanding student requires not only a solid medical theory, but also a basic professional quality, namely clinical competence, communication skills, and ethics. This poses greater challenges for nursing schools. How to change teaching methods so that nursing students can obtain good first-aid knowledge and skills to become qualified for clinical work in school have become a hot issue for nursing educators. In the late 20th century, problem-based learning (PBL) gradually developed. PBL, whose full English name is Problem Based Learning, is the same title-oriented teaching methods. PBL first originated in medical education in the 1950 s and has become a popular international teaching method ${ }^{[3]}$. PBL is a student-centered approach to education. It sets learning to complex, meaningful contexts. By allowing learners to work together to solve real-world problems, students develop problem-solving skills and develop self-learning skills ${ }^{[4]}$.

In this study, the LBL teaching method, PBL and LBL dual-track teaching method were applied to the teaching of obstetrics and gynecology and the teaching effects of the two teaching methods were discussed. 


\section{Object and Methods}

Research Object. The objective sampling method was used to select the 2015 undergraduate nursing students at Xi'an Foreign Affairs College. A random sample of 60 people was randomly divided into two groups: LBL group (A group) and LBL+PBL group (B group), 30 in each group. The statistical analysis of the age and academic performance of the two groups showed no significant difference $(\mathrm{P}>0.05)$, and they were comparable.

Method. The teaching contents of the two groups are the same. Refer to the teaching contents and syllabus of the "Gynecology and Obstetrics Nursing Science".

The LBL group was taught using the traditional teaching method: the teaching syllabus was established, and the teacher team prepared the lesson before the implementation; the teacher taught the basic knowledge, the cause of the disease, clinical symptoms, treatment and nursing measures.

The LBL+PBL group was taught using the LBL+PBL dual-track method: Formulate syllabus and write cases; The teacher team organizes lesson preparation in the implementation month and designs and compiles cases according to the pilot content; Teachers teach basic knowledge about diseases; distribute cases, group students, find data, analyze cases, and formulate solutions; Class discussion, exchange, share information resources, teacher comments, promote in-depth thinking and continue to expand learning.

Evaluation method: The composition of scores in the two groups is the same: theoretical examinations account for $70 \%$, and clinical problems account for $30 \%$. The examination methods of the two groups are the same. The theoretical examinations are closed book examinations. The two groups of examination papers are the same. They are all composed of three parts: a multiple-choice question, a short answer question, and a case analysis question; The review of clinical issues is a time-limited open-book exam that uses learned knowledge to write a review of the literature. Theoretical examinations are reviewed in accordance with standard answers, and clinical questions are summarized to formulate a unified evaluation content and evaluation criteria, which are reviewed by two fixed teachers.

Statistical Analysis. Each evaluation result was entered into a computer using Excel 2000. Statistical analysis was performed using the SPSS18.0 statistical software and a two-sample u test. The statistical significance was set at $\alpha=0.05$, i.e., when $\mathrm{P}<0.05$, the statistics were statistically significant. difference. The average and standard deviations are used to describe the concentrated and discrete trends of results.

\section{Result}

Comparing the results of basic questions and comprehensive application questions: The 2015 grade undergraduate nursing student obstetrics and gynecology nursing examination questions include basic questions and comprehensive questions. The basic questions refer to the questions that has a definite answer in the book; the comprehensive question refers to the question and summary that requires a comprehensive analysis and answer without explicit answers in the book. The results are shown in Table 1. There was no significant difference in the basic questions between the two groups, but there were significant differences between the two groups.

Table 12015 Grade Obstetrics and Gynecology Nursing Achievement

\begin{tabular}{lccc}
\hline Group & People & Basic Questions & Comprehensive Questions \\
\hline Group LBL & 77 & $53.41 \pm 12.87$ & $12.49 \pm 9.11$ \\
Group PBL+LBL & 78 & $58.64 \pm 14.15$ & $16.34 \pm 11.84$ \\
u value & & 0.38 & 4.21 \\
P value & & $>0.24$ & $<0.001$ \\
\hline
\end{tabular}




\section{Discussion}

In the traditional LBL teaching model, the teaching is centered on the classroom-teacher-textbook. The curriculum teaching is still mostly based on the "teaching + blackboard + examination" model that mainly teaches theoretical knowledge. The integration between theory and practice learning is not enough. Students simply learn for exams, do not apply the knowledge they learn, they do not ask questions themselves and they solve problems, and their ability to work is limited ${ }^{[5]}$. This kind of education can hardly cultivate students' initiative and enthusiasm, neglecting the cultivation of students' innovative spirit and practical ability, and forming a situation of how much to teach, how much to learn, how to teach, how to learn, not to teach. This kind of education is difficult to cultivate students' initiative and enthusiasm, neglecting the cultivation of students' innovative spirit and practical ability, and forming a situation of how much to teach, how much to learn, how to teach, how to learn, not to teach. In this passive learning environment, students are often placed in a state of passive acceptance of knowledge, which can easily lead to students' learning fatigue, difficulty in stimulating their enthusiasm and creativity, and unfavorable training of students' application ability. Therefore, this is not conducive to the development of application-oriented nursing talents ${ }^{[6]}$.

The use of the dual-track approach of LBL+PBL combines learning with tasks or problems, allowing learners to engage in complex and meaningful problem scenarios, and solving problems through learner's autonomous exploration and cooperation. The scientific knowledge behind the question forms the skills to solve the problem and the ability to learn independently ${ }^{[7]}$. In this process of autonomous inquiry, students are the discoverers of problems and knowledge. Teachers only play a guiding role and have completed the transition from "teaching-centered" to "student-centered". This gives students plenty of room to play and greatly enhances students' initiative and creativity. More importantly, through thinking, discussing, and summarizing problems, students are allowed to experience the duties and requirements of being a nurse and learn clinical thinking and master the methods to apply knowledge.

In the PBL teaching model, the role of the teacher is also changing. They are no longer the imparter of knowledge, but the guide for students to learn independently. Students are no longer passive learners, but gradually become leaders in learning during problem identification and resolution $^{[8]}$. Through the LBL+PBL dual-track approach, teachers use questions to inspire students' curiosity and curiosity and mobilize their initiative in learning so as to enlighten students on positive thinking, make them full of vitality, full of speculative skills, and actively participate in learning. Through the process of asking questions, establishing hypotheses, autonomous learning, collecting information, and validating hypotheses, students can effectively integrate theory and practice through the cycle of "practice-theory-re-practice-re-theory". This trains students' clinical thinking in connection with practice, improves their ability to analyze and deal with practical problems, and promotes the effective use of knowledge ${ }^{[9]}$.

The LBL+PBL dual-track teaching method has many advantages over traditional teaching methods. It breaks the boundaries of the subject by means of questions, has comprehensive and flexible features, integrates teaching quality and quality education in one, and is an effective method for cultivating knowledge, ability and quality ${ }^{[10]}$. The results in Table 1 show that using the LBL+PBL dual-track approach teaches students to perform better than the students taught in the LBL approach.

According to comprehensive analysis, the dual-track teaching method combined with LBL+PBL is a new teaching model. It has reformed the traditional teaching model in the past, which is conducive to improving the medical students' learning ability, communication skills, and comprehensive ability to comprehensively analyze problems. It is a promising teaching method and deserves our vigorous promotion and development. 


\section{References}

[1] Jing Jin, Guowei Zhang. The Attempt of PBL+PLTL Teaching Mode in Clinical Teaching of Obstetrics and Gynecology [J]. Basic Medical Education, 2011, 13(8): 748-749.

[2] Donner RS, Bickley H. Problem-based learning in Americanmedical education: an overview [J]. Bull Med Libr Assoc, 2013, 81(3): 294-298.

[3] Gwee MC. problem -based learning: a strategic learningsystem design for the education of healthcare professionalsin the 21st century [J]. Kaohsiung J Med Sci, 2009, 25 (5): 231-239.

[4] Hitchcock MA, My lona ZH. Teaching facully to conduct problem-based learning [J]. Teaching and Learning In Medicine, 2000, 12 (1): 52-57.

[5] Wei Deng, Xuejie Zhang. Application of PBL Teaching Method in Nursing Teaching of Obstetrics and Gynecology [J]. Western Medicine, 2011, 23(3): 595-596.

[6] Lin Wang, Xiaoyan Xin, Biliang Chen. On the Teaching Method of Obstetrics [J]. Northwest Medical Education, 2007, 15(5):965-967.

[7] Jinmei Xu, Suding Fei, Guijuan Liu, et al. TBL The Application of LBL Mode in Higher Vocational "Emergency and Critical Care" Teaching [J]. People's Liberation Army Nursing Journal, 2013,30(24):65-68.

[8] Yan Cheng, Hong Zhang. Discussion on the Reform of Practical Teaching Methods in the College of Nursing and Obstetrics Nursing [J]. Inner Mongolia Traditional Chinese Medicine, 2008, 22:60.

[9] Junhui Wang, Yueya Li, Jianping Luo, et al. Exploring the Open Teaching Reform of Basic Biology Experiments [J]. Experimental Technology and Management, 2007, 24(6): 120-123.

[10] Wang Zhen, Zhang Liqiu, Sun Dezhi. Undergraduate Students' Creative Ability Training Model Design [J]. China Forestry Education, 2010, 28(4): 1-5. 